\title{
Sustainable Energy and RES Implementation in Russia
}

\author{
Dinara Orlova ${ }^{1, *}$, Sofya Smolyakova $^{2}$, and Aleksy Kwilinski ${ }^{3}$ \\ ${ }^{1}$ Financial University under the Government of the Russian Federation, Economics Department, \\ 125993 Moscow, Leningradsky Prospekt 49, Russian Federation \\ ${ }^{2}$ Financial University under the Government of the Russian Federation, Faculty of International \\ economic relations, 125993 Moscow, Leningradsky Prospekt 49, Russian Federation \\ ${ }^{3}$ The London Academy of Science and Business, 120 Baker Street, London, W1U 6TU, United \\ Kingdom
}

\begin{abstract}
Nowadays, the world is undergoing the fourth energy transition process. The global climate agenda, decarbonization tendencies and the necessity to reduce $\mathrm{CO} 2$ emissions in order to meet the Paris Climate Agreement criteria are the dominant motives of the sustainable energy development. This article is devoted to analysing the implementation of renewable energy sources in Russian energy sector. The prospect aims are to identify the strengths, to assess the prospects for energy transition, to reveal key issues related to emerging industry and present recommendations on how to address them. It was found out that the implementation of RES is of high potential, especially in certain Russian regions. The key problems that hinder the RES development include low awareness, weak development policy, specific weather conditions, the lack of cutting-edge technologies etc. In this regard, it was suggested to strengthen the regulation within the climate policy, increase investments in green projects and stocks, accelerate the technological development and take other measures to support the emerging industry, along with general awareness-raising in the renewable energy sector.
\end{abstract}

\section{Introduction}

Nowadays the world economy is experiencing the fourth energy transition, but instead of one technological revolution, there is a whole complex of technological breakthroughs based on the 3 Ds related to Energy: Decarbonization, Digitization and Decentralization. The core of current energy transition is the idea of fulfilling the needs of humanity without compromising the environment. For this reason, in today's world the economic and ecological development are inextricably linked. In modern conditions the process of transition to 'green' trends are to be a key component of sustainable development strategies of advanced economies. The past decade has laid a powerful impulse for transforming the energy system. The appearance of emerging technologies and increased focus on climate change have firmly anchored the global attention to decarbonization of the energy system. During the gradual recovery of

* Corresponding author: $\underline{\text { drorlova } @ \text { fa.ru }}$ 
economies, it should be borne in mind that a temporary improvement in the environmental situation does not exclude the need to combat the consequences of climate change. The Green Growth Strategy, which means stimulating economic development with ensuring that natural assets continue to provide the resources and environmental services on which human's wellbeing relies, becomes extremely popular [1]. The issue of climate changing, the massive $\mathrm{CO} 2$ emissions in particular, is not only the reason of global ecological disaster, but is also closely associated with such categories as economic growth and technical progress, so determines the functioning of major economic industries. Furthermore, the need to conform to the requirements of Paris Climate Agreement and to maintain position on the international arena demands taking actions. Energy is a key element of the growth process of any economy as it manages everyday household activities together with industrial ones that form the basis upon which the economy is built. In this regard, more countries realise how essential it is to transform traditional energy systems and focus on applying alternative energy sources, including renewable energy sources (RES).

According to International Energy Agency (IEA), the commissioning of new renewable energy-based capacities increased by more than $45 \%$ in 2020 as compared to 2019 , and this tendency will continue in 2021-2022 [2]. In accordance with the report, published by Angora Energiewende and Ember, in 2020 RES, for the first time ever, overtook fossil fuels to become the EU's main source of electricity (Fig.1). The share of RES in gross electricity generation accounted for $38.2 \%$, which means a significant step towards the decarbonized future. Renewables have reached the leading positions due to the continued growth of wind and solar energy, which increased generation in 2020, despite the corona crisis, by $9 \%$ and $15 \%$, respectively. They provided almost a fifth (19\%) of all electricity in the EU last year: a share of wind made $14 \%$, and solar accounted for $5 \%$. The volume of production in the hydropower industry remained unchanged, the development of bioenergy has stalled, the report noted [3].

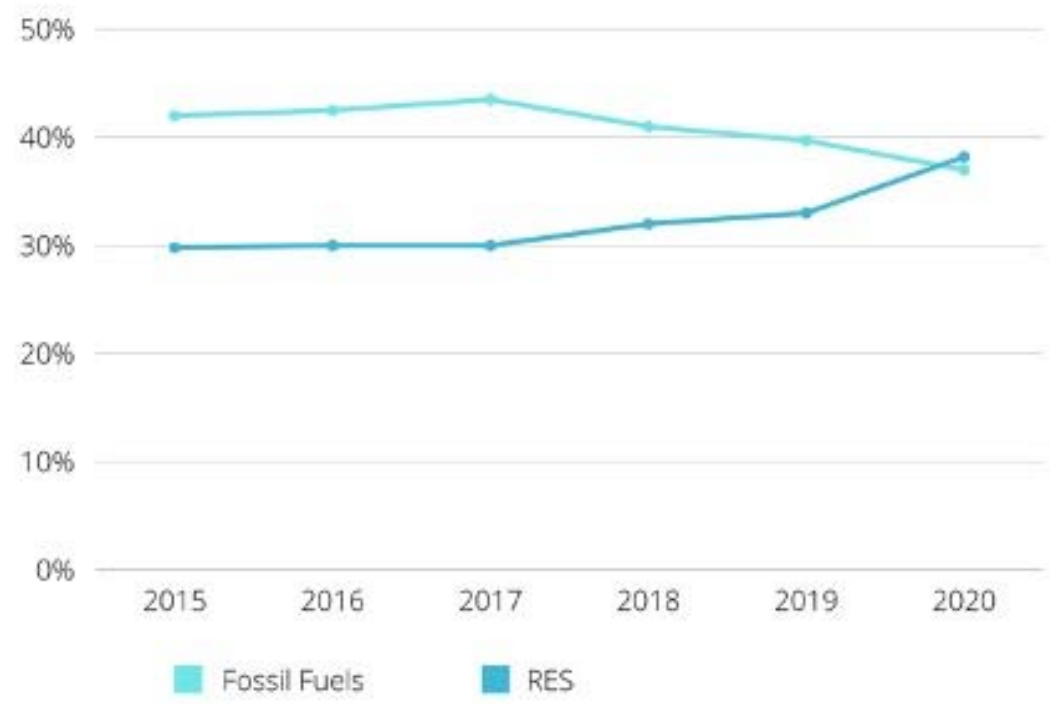

Fig. 1. A share of electricity production in the EU-27, 2020, \%.

Turning to Russia, when it comes to energy transition, the general situation may be considered as uncertain. The steady increase of prices for energy resources, such as coal, fuel and gas, makes RES even more attractive. In spite of the opinion that solar and wind energy is not the most adequate solution for Russian energy sector, the renewable energy industry, 
formed in the country since 2013, already plays an important role. Due to major investments (about 650 billion roubles), significant multiplier effects appear in the economy, and renewable energy acts as one of the drivers of sustainable economic and social development.

However, despite the high potential, the level of sustainable energy development in Russia is relatively lower than that in leading countries. Being among leading fossil fuels exporters, Russia earns a significant part of revenues from the economy, and renewable energy acts selling abroad oil, fuels, natural gas and coal. This hinders the development of alternative energy sources and poses challenges to the energy transition processes. The country needs to shift the vector due to the started growing green trends, especially in countries-trading partners. Coal exports from Russia in April 2021 decreased by 34.6\% compared to the same period in 2020 and amounted to $\$ 976.9$ million, and companies ' revenues from the export of fuels from Russia in January-April 2021 decreased by $0.2 \%$ [4]. However, as a nation with advanced steel, naval, chemical and other industries, it is impossible for Russia to fall behind in the basic industrial sector and lose the title of an important player in the global energy system, when most countries benefit economically from industrial and technological progress in the field of renewable energy sources and energy storage technologies.

\section{Current Situation}

As it was already mentioned, while the economic development level is increasing, in the countries with advanced economies energy transition processes take place, particularly the use of RES, the implementation of new technologies, the rejection of $\mathrm{CO} 2$ consumption, the launch of 'green 'projects. For instance, in Japan, which is famous for its green growthoriented climate policy, introduction of advanced technologies and elaboration of alternative energy sources, it is planned to employ hydrogen as a replacement for carbon dioxide, in particular, to build about 8,500 hydrogen filling stations by 2030 and to abandon using fuelpowered vehicles (it is estimated that by 2030 , fuel-powered cars will account for about $20 \%$ of the total number) [5]. These technologies are also planned to be introduced in the field of sea transportation.

If to compare with Russia, by the results of the World Economic Forum (WEF), in the rating of Energy Transition Index (ETI) the country took only $73^{\text {rd }}$ place, which means that current adopted measures are not effective enough [6]. According to Enerdata, the share of renewables in electricity generation accounts for only $20.3 \%$, which is only $4 \%$ higher than in 2015 [7]. However, the share of solar and wind power is only $0.3 \%$, which is extremely low (Fig. 2).

In April 2020, Russia approved a new energy strategy for the period up to 2035. Both scenarios of the energy strategy assume a gradual increase in the share of RES in the global energy balance, however, the document notes that fossil fuels will still continue to form the basis of the global fuel and energy balance in 2035. In accordance with the strategy, Russia will strive for stability regarding the extraction of fossil fuels and strengthen its international position in energy markets. The main measures planned are to improve the national renewable energy standards, to support the export of Russian equipment for renewable energy, to enhance regulatory mechanisms, as well as stimulate voluntary demand for renewable energy [8]. Nowadays in Russia there runs a 'DPM VIE' program - a capacitybased support scheme (CBSS), the program to stimulate a RES-generation based on power supply agreements. The program envisages a competitive selection of various investment projects, related to the construction of generating facilities based on the use of RES. 2,783.39 MW of renewable energy generation facilities were put into operation within this program, in particular, 483 MW due to SPP, 1278.99 due to WPP and $21 \mathrm{MW}$ due to small hydropower plants (as of 1.07.2021). Furthermore, according to the official data, the dynamic of launching 
new RES-based capacities tends to be positive [9]. In 2015, renewables accounted for only $55 \mathrm{MW}$ and was limited to solar power, and in 2020 1,195 MW were implemented (Fig. 3).

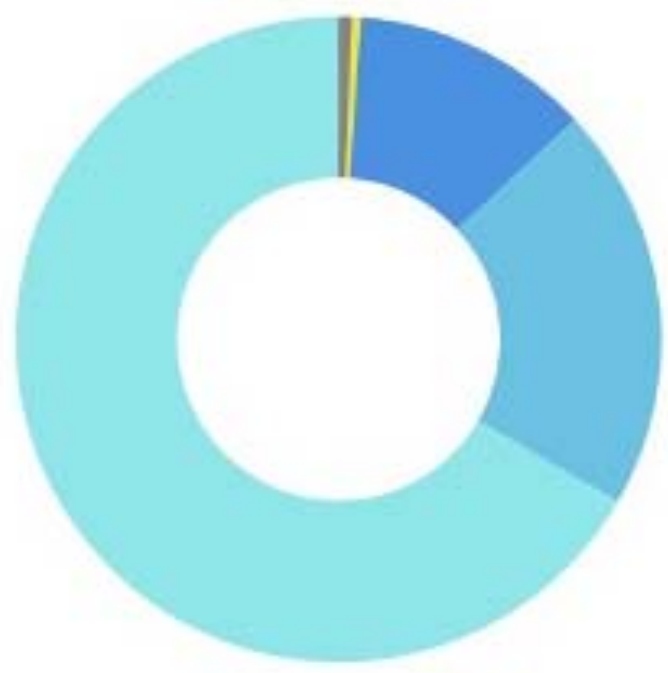

solar power $[0.7 \%]$ wind power $(0.4 \%]$ nuclear power $(12 \%)$

Indro power (20.3\%) thermoelectric pawer (66.6\%)

Fig. 2. The share of electricity production by source in Russia, 2020, $\%$.

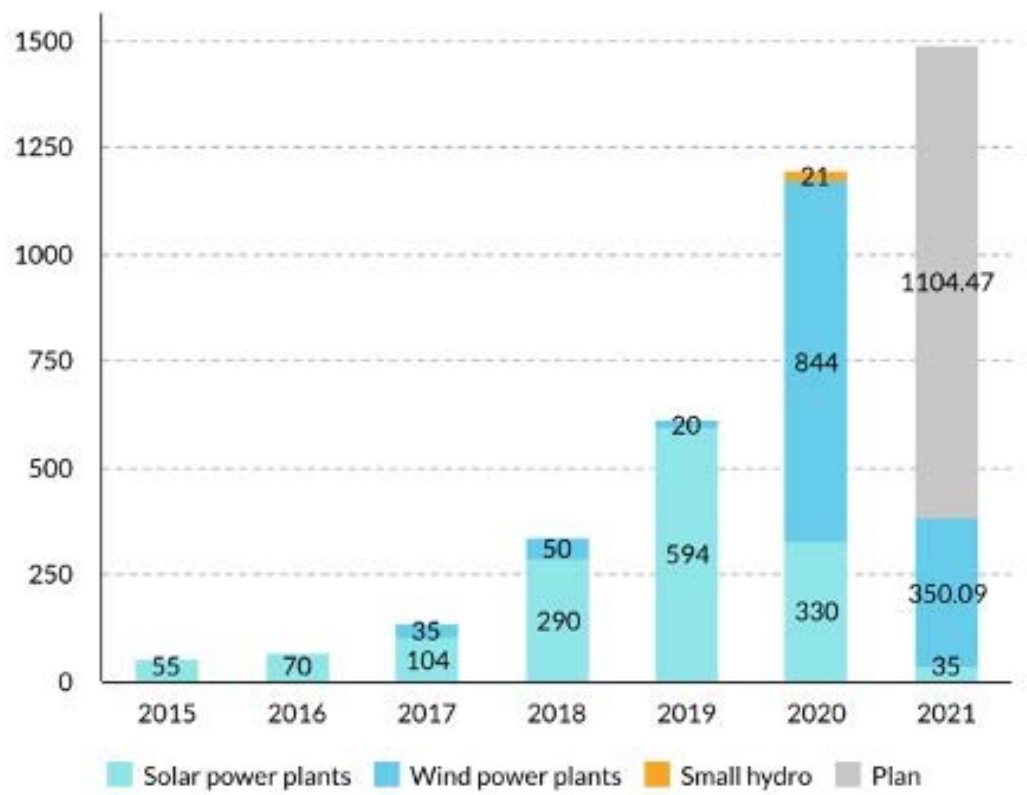

Fig. 3. Dynamics of power plants inputs based on RES (RES PDM), MW. 
The first stage of the program provided not only a significant inflow of investments, but also the accelerated development of industrial production of equipment. The country has acquired new competencies in constructing and operating the generating facilities. Nevertheless, the government decided to cut the volume of the new green generation support program - DPM 2.0 - by 10\%: support for the renewable energy sector in 2025-2035 will be reduced from 400 to 360 billion roubles. This decision may be considered strange, while advanced economies are enhancing 'green' investments in RES. Furthermore, the requirements for localization of equipment became tightened, the share of domestic equipment must be $90 \%$ against the current $65-70 \%$, along with its mandatory export (Fig. 4) [10].

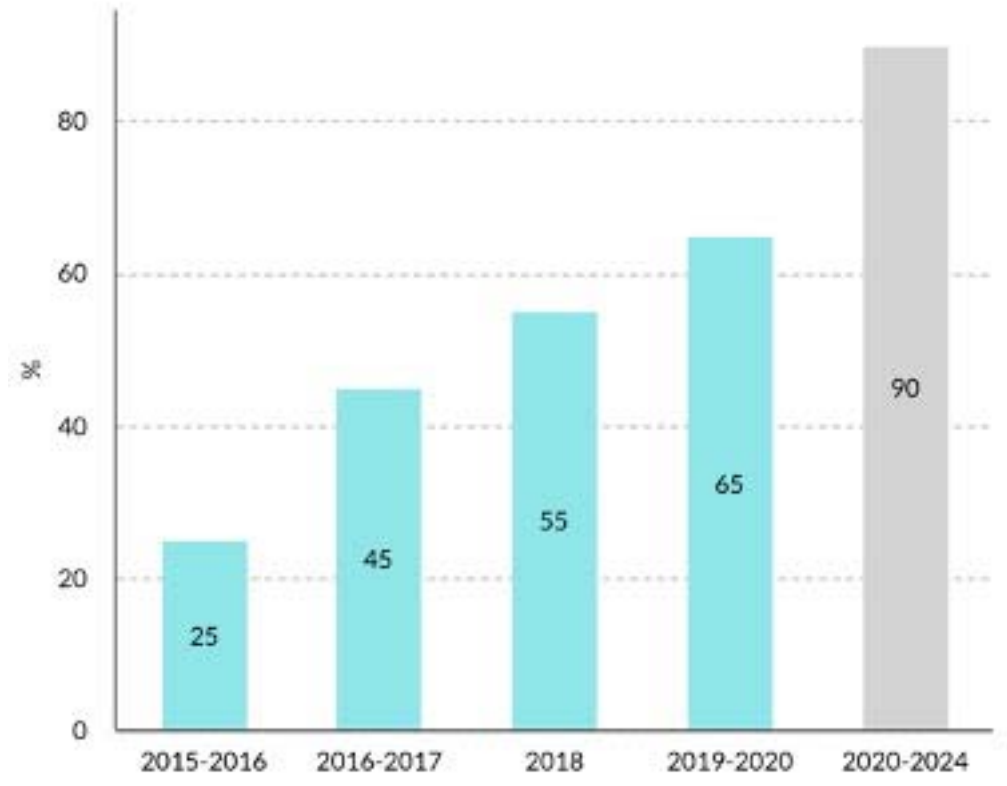

Fig. 4. Target indicators for the degree of the production localization for the RES equipment, $\%$.

In this regard, the opinions differed. On the one hand, the previous capacity selection demonstrated a significant reduction in capital costs for installing solar and wind-based generation and it is a sensible solution to reduce funding for this purpose. However, adopted measures may deprive of capacity growth, and new requirements for localization may lead to the need of additional investments in industrial plants, which cannot be recouped while the domestic market is declining. Moreover, it can cause the closure of new enterprises and, as a consequence, job losses.

At present, the main institution engaged in RES is Russian Renewable Energy Development Association (RREDA). It is a non-profit organisation that represents the participants' interests of Russian renewable energy sector and contributes to establishing a favourable investment climate and promoting the idea of using renewable energy sources [9]. The priority areas of the RREDA for its activity are:

- establishing partnership with public authorities for creating a favourable investment climate;

- carrying out activities related to the promotion of RES;

- developing international cooperation in renewable industry etc. [11]. 
Turning to government, it also endeavours to straighten the industry and to accelerate the pace of moving towards the next energy transition. However, there are several concerns limiting this process in Russia which still needed to be addressed.

\section{The Main Issues and Possible Solutions}

One of the existing issues of developing RES in Russia is the lack of awareness and the wrong policy in sustainable development. Unfortunately, the renewables in the country have not yet been accorded the proper significance and impact. Despite the existing programs of support, the investment in RES is decreasing. Furthermore, the sums invested in 'dirty 'manufacturing are growing. This is due to Russian economic reliance on export of fossil fuels, which plays a pivotal (and mostly negative) role in general economic development. Regrettably, instead of supporting the most backward areas and proceeding to steps towards reducing backlog, the strategy of the country is to continue expanding this sector, which results in hindering the transition process and the economy becoming even more dependent.

In this situation, the possible long-term problem for Russia is a decline in demand for fossil fuels, which is connected with today's global climate agenda and the terms of Paris Agreement. It is clear that in many countries with advanced economies (mostly located in Europe) current energy transition goes more rapidly. For example, in Germany the share of RES in energy generation accounted for $45 \%$, in Denmark - 78\%, in Austria - 79\% [3]. For Russia, with its serious aforementioned economic reliance on export of fossil fuels, it is a severe threat.

In this context, it is needed to change the policy and abandon this development path, as well as become better informed in the area of RES. In particular, the possible solution is to implement certain restricting measures, related to 'dirty 'production. For instance, the introduction of emission restrictions or expanding the mechanism of ETS (Emission Trading System) can contribute to solving two significant issues. Firstly, it is a great opportunity to reduce $\mathrm{CO} 2$ emissions and accelerate the fulfilment of the Paris Agreement's terms. Secondly, the introduction of restrictions can stimulate investments in other areas, including alternative energy sources, renewable energy, and change the focus to other sectors. All this will allow diversifying the economy, reducing the level of dependence on fossil fuels, and will also contribute to attracting investment in currently underdeveloped areas. Furthermore, it is important to foster strong international relationships in the renewable industry, since integration of various countries into this process contributes to forming international agreements in the field of RES and provides an opportunity of exchanging and transferring technologies.

The next important issue is the problem of disposing the industrial waste: distrusted equipment, such as fractured blades of wind power generators, solar panels etc. For instance, about $70 \%$ of all wind power generators currently existing (almost 400GW from approximately $600 \mathrm{GW}$ ) and more than $90 \%$ of solar photovoltaic systems (400GW out of $500 \mathrm{GW}$ ) were launched into service over the last 10 years. It means that the issue of recycling will appear over the next 10-20 years. This issue may also pose a challenge to the metallurgical industry. In this regard, it is important to take measures now and to prepare in advance.

The blades of wind power generators are made from composite materials and demand the specific technology of disposing. Today, by no means, all existing methods of recycling the blades are available on an industrial scale and may be considered competitive. For this reason, the process of developing new, more advanced and modern technology in this area, especially in Europe, is under way [12-20]. According to the report, made by WindEurope, Cefic and EuCIA, today composite materials are being recycled mostly through cement co-processing, where the mineral components are reused in the cement, and the organic fraction replaces 
coal as a fuel. The advantage of this process is also the reduction of the $\mathrm{CO} 2$ output of the cement manufacturing process (up to $16 \%$ if composites represent $75 \%$ of cement raw materials) [21]. However, the industry needs additional solutions regarding alternative mechanisms of recycling; therefore, it is crucial to continue technological development in this area, including international cooperation. Another possible option of using old blades is to construct various infrastructure objects, for instance, children's playgrounds.

Turning to solar batteries, there is also a room for development. In accordance with the US National Renewable Energy Laboratory (NREL), by 2030 the volume of worn-out solar panels will exceed 1 million tons, and by $2050-78$ million tons (Fig. 5) [22].

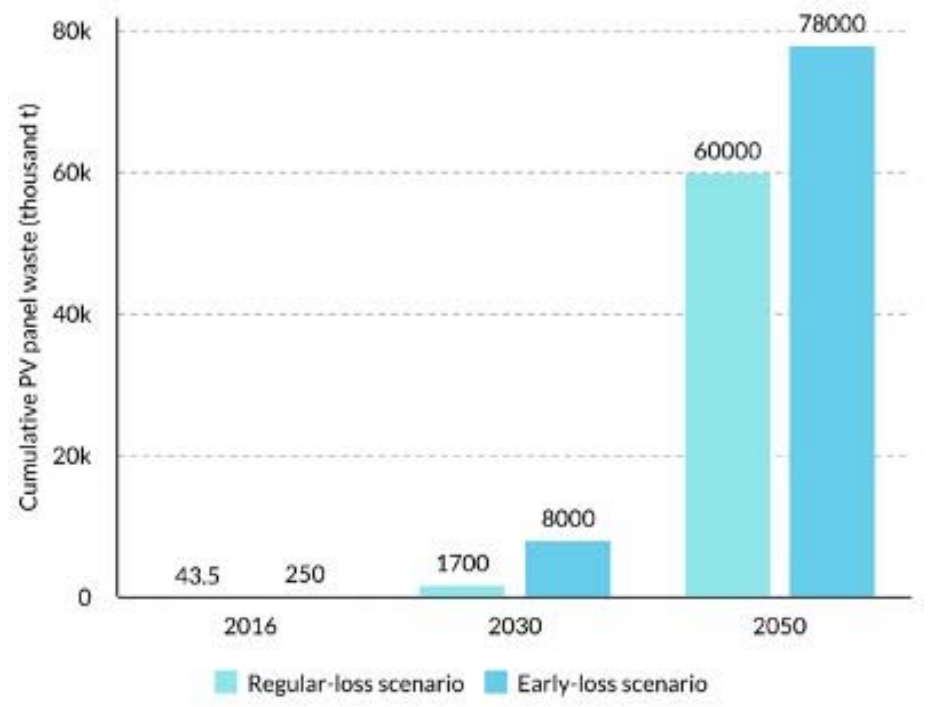

Fig. 5. An overview of global PV panel waste projections, 2016-2050.

The main problem of recycling here is the price: disposing component parts of solar plants is less financially profitable than storing them in special warehouses. For this reason, the industry requires efficient technologies to extract and clean the silicon and silver contained in the panels, which will convert the recycling process in more cost-effective. Nowadays, there are several companies around the world engaged in developing such methods, but, unfortunately, none of them are in Russia. More importantly, there is already sophisticated equipment which provides an opportunity to increase the share of reusable materials to $95 \%$.

In this regard, establishing international relationships, building partnerships and creating cross-industry alliances on the field of disposing the industrial waste is to play a vital role for Russia. Obviously, it is important to conduct local studies on refining existing technologies, but, in the light of tight pressure involved, the exchange of technologies is the most effective option. It is also crucial to enhance funding and financial support for speeding up innovations. According to Cefic Director General, Marco Mensink, "investing in renewable energy production and circular solutions should be one of the key drivers of the post-COVID-19 economic recovery" [22].

Another issue particularly available in Russia is specific climate. Renewable energy sources are very sensitive to weather conditions; hence, it is necessary to build a reserve as extra generating capacities if generation is suddenly interrupted. It requires significant additional expenses, and the economic efficiency of RES turns out to be considerably lower. Moreover, in particular regions, such as Siberia or Far East, the temperature in winter can 
fall below $-40 \mathrm{C}$, which can be critical for stable functioning of energy facilities or electric vehicles.

However, the practice shows that it is a solvable problem. For instance, the research showed that Krasnoyarsk Region, a territory with harsh northern climate, has the potential to apply solar power in the region, which, combined with other renewable sources of energy, outlines a solution for thinly populated, agricultural and remote areas. Both solar and wind power appear to be promising supplemental sources of energy for industrialized territories [23].

Another example is the first electric buses introduced for the first time in Moscow in September 2018. In Russia, the price of electricity is low, and the grid is widespread. Thus, shifting mobility from internal combustion engine to electric vehicles is an economically convenient opportunity starting from companies and cities operating large vehicle fleets [24]. Less than one year later, over 180 of e-buses were deployed on 13 e-bus routes, carrying more than 80,000 passengers a day. Starting from 2021, Moscow's public transport company will only purchase electric buses, discontinuing purchasing the diesel ICE ones [25].

There are clearly other potential issues for Russian renewable energy industry that may appear in the next 10-20 years. These include the visual impact, the elimination of traditional and cultural landscapes, high material capacity of the constructions, vulnerability of structures, possible health effects etc. However, the main barrier is the scarcity of economic opportunities and cutting-edge technologies, and the endeavours to eliminate this backlog should be enhanced.

\section{Promising Areas}

Nevertheless, there are several aspects that increase the potential of Russian renewable energy development and contribute to the energy transition process. The first aspect is the vast territory. Various constructions of renewable energy capacities are quite massive and require large tracts. For instance, a wind farm with $10 \mathrm{MW}$ of generating capacity requires approximately $10 \mathrm{~km} 2$ of space, a solar power farm needs about $1 \mathrm{~km} 2$. While other countries may face substantial problems with regard to the deployment of generating capacities, Russia has an advantage here. However, in spite of the opportunity of placing a significant amount of wind and solar farms, there are more remote territories and under-developed regions in need of energy supply.

In this regard, there are areas potentially favourable for placing wind and power farms or micro hydro plants, including places, where the process of traditional energy supply is to be problematic (Fig. 6). The most potentially favourable places include Altai region, Primorye region on the Far East, Russian South (North Caucasus), Kola Peninsula and remote areas, such as Kaliningrad, Kuril Islands etc. These territories possess appropriate weather conditions, tracts and other factors for successful implementation of RES. For example, Primorye is suitable for wind generation. Nowadays, there are also major government support programs and active subsidy of developing distant areas, including Far East, infrastructurebuilding and creating 'priority development areas [26], it can stimulate investment and accelerate the process of constructing there renewable power farms. Now it is planned to build there a wind farm using a cutting-edge technology that will allow making the installation 2.5 times more powerful and lead to significant production cost decline.

The Kola Peninsula, due to its location and climatic specifics, is also suitable for wind power generation, along with small hydro generation. Moreover, its situation near the border provides an opportunity for international transboundary cooperation. North Caucasus is appropriate for all kinds of RES. Furthermore, due to the high level of unemployment and population density, the region will benefit from emerging industry. 


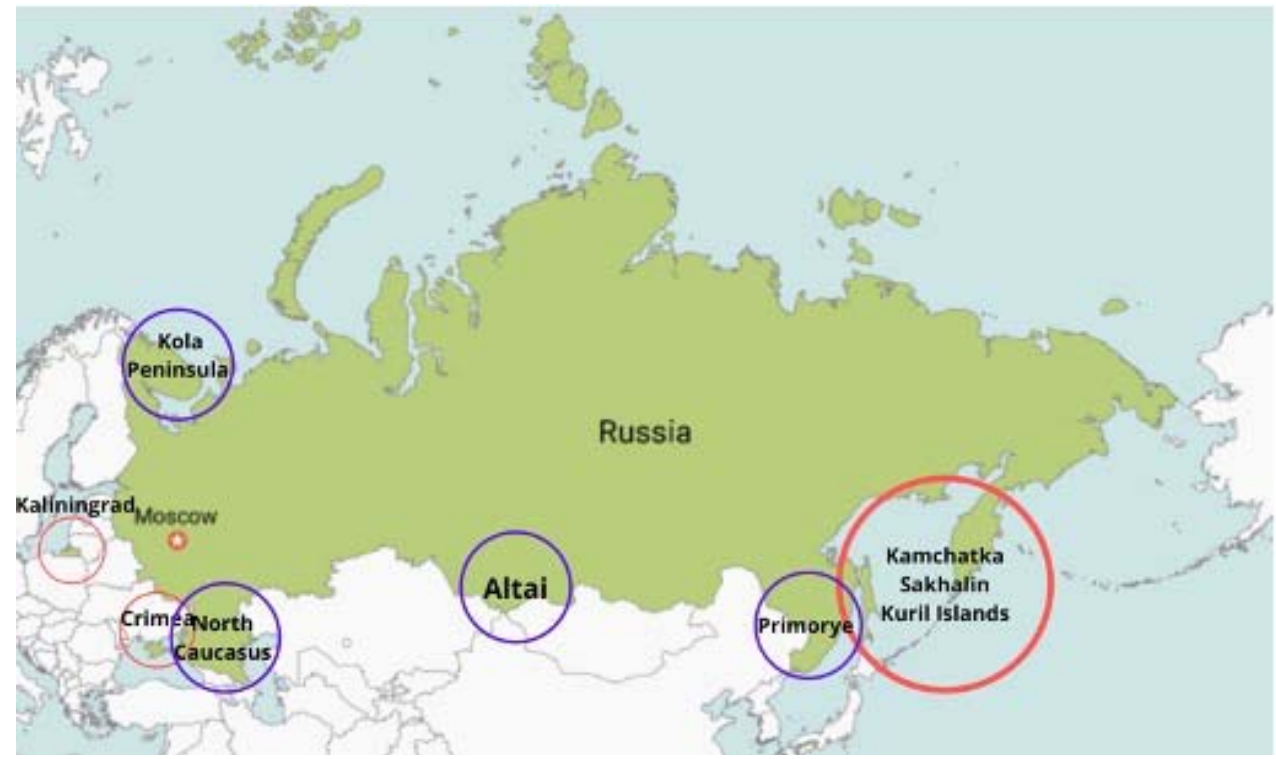

Fig. 6. Areas potentially favourable for implementing RES.

Speaking about Altai region, the plenty of small hydro power plans are functioning here, and a lot of remote settlements that rely largely on small hydro generators for energy production, which is clean, available and affordable. However, there are no sufficient investment flows to support the region, as the projects are expensive and risky. Despite the successful implementation of RES in the region, the issue of developing small-scale energy is of the paramount priority, since today the region is energy deficient. The main problem is the lack of financial support for the projects' execution for constructing hydroelectric power plants on small rivers.

Turning to remote areas, as it was already mentioned, the mechanism of energy supply there is complicated; hence, apart from having a great potential of developing RES, these regions need off-grid energy provision to reduce costs and minimize risks. Over the past 5 years, the demand for electricity on the Kuril Islands has increased by a quarter. By 2025, it is projected to rise by 1.7 times. In this regard, various projects have been developed in the field of electric power, including those based on renewable energy sources that are seen as a future alternative to the expensive delivery of fuel to the islands for diesel stations. The implementation of renewable energy on the islands is a part of the program of socio-economic development, as well as public-private partnership mechanisms. Unlike the Kuril Islands, where the major part of the projects receives government funding, the expenses are covered by private organisations and investors. Nowadays, there are only 4 objects of green generation, accounting for $4.1 \mathrm{MW}$, but within the carbon neutrality project, it is planned to significantly increase in share of RES in the region's energy balance. Generally, the introduction of new green generation facilities is projected to reduce the carbon footprint of the Sakhalin and Kuril electric power complex by about 7\%. Kaliningrad is also a promising area for locating low-carbon development. The proximity to European export markets, high scientific and technical potential, developed transport infrastructure, the availability of energy resources etc. increase the potential of RES implementation. By 2025, the Baltic countries, which border with Kaliningrad, intend to abandon the traditional energy communications and successfully move towards this goal by increasing the share of renewable energy sources in the energy balance. Therefore, the positions of Russian energy importers in the Baltic energy market are becoming weaker. However, it is not the main reason of RES development in this region. The Kaliningrad Region has unique opportunities 
for hosting offshore wind energy power plants. Valery Beley, a professor at the Kaliningrad Technical University says that "electricity generation by wind farms is $25-40 \%$ higher than on land, provided that they are 3-5 km away from the shore and a longer distance, at which a weaker land wind has time to transform into a stronger sea wind". In accordance with the research of local scientists, it is possible to install wind turbines with a total capacity of 300 MW in the coastal zone alone, which will cover about $30 \%$ of the region's electricity needs [27].

Generally, if to roughly divide the territory into two parts, northern and southern, the potentially optimal RES may be identified. The northern belt is characterized by extensive forests; hence it is to be a favourable area for bioenergy generation based on timber and peat processing. The southern belt, according to weather conditions, has the capacity to exploit solar energy generation. Furthermore, a significant number of regions located in the south have high rural population densities. This is the prerequisite for the further development of bio generation based on agricultural waste. This is a promising opportunity to employ renewable fuels of biological origin, such as fuelwood, charcoal, energy crops etc.

In sum, the Russian territory is suitable for RES implementation, especially in particular regions. The large area, climate specifics, volatility of weather conditions, different densities etc. may complicate the process of RES adoption, however, at competent approach, these aspects may be turned into advantages.

\section{Conclusion}

Nowadays, the energy generation by means of the sun, wind and water power is ubiquitously used, while the era of fossil energy sources is facing evident limitations. Today green generation, with the share of 10\% (SES and WPP) in the total global electricity production, has a huge impact on the economic and social development processes of advanced economies, the new industry is emerging. This is what is called a global energy transition process, which, in accordance with scientific expectations, will occur in the first half of the XXI century. Another significant motive of energy transition is global climate agenda. Regarding the ecological aspects, the monetary equivalent of environmental damage from RES is significantly lower than that of fossil energy. In spite of the visible reductions in the greenhouse gas emissions in predominantly developed countries, the volume of global emissions is increasing every year. A significant reduction in emissions in 2020 (up to 31.1 Gt compared to 33.4 Gt in 2019) can be definitely attributed to the global crisis caused by the Covid-19 pandemic. Suspensions on manufacture, deceleration of the international markets functioning, the disruption of transportation - all this had a significant impact on reducing emissions by $8.6 \%$. In this regard, it is important to take into account both the priorities of a particular economy and global priorities related to the climate agenda.

There are various scenarios for the development of renewable energy in Russia, however it can be definitely said that RES have a high potential in particular Russian regions, with economic feasibility inherent in these territories. This article defines such regions as potentially favourable and includes Altai region, Primorye region on the Far East, Russian South (North Caucasus), Kola Peninsula and remote areas, such as Kaliningrad, Kuril Islands, Sakhalin among these territories.

The potential issues that can appear during the current energy transition process were also identified as outlined:

- the lack of awareness

- the wrong policy in sustainable development

- the industrial waste processing

- climate specifics 
- a significant technology gap.

In this regard, the recommendations resulting from the analyses made were presented in this article and are summarized below:

- The implementation of certain restricting measures related to 'dirty 'production, including the introduction of emission restrictions and expanding the mechanism of ETS (Emission Trading System), that can contribute to the $\mathrm{CO} 2$ emissions reduction, acceleration the fulfilment of the Paris Agreement's terms and be a stimulus to the investments in alternative energy sources;

- The development of alternative mechanisms of recycling the blades of wind generators and solar panels, and establishing international relations in case of cooperation and exchange of technologies, alternative application of worn-out equipment;

- The expansion of green projects, especially in the most feasible regions, budgetary allocations for preferential credit to renewable energy industry, along with stimulating investment by issuing green bonds, tax deduction provision and creating Special Economic Zones in potentially favourable areas;

- General awareness-raising in the renewable energy sector, introducing staff training programmes to avoid the lack of professionals in the emerging industry and future employment creation, which will also contribute to socio-economic development;

Taking everything into account, the growth of the renewable energy share in Russia can be facilitated by the scientific reserve in the renewable energy sector, as well as domestic equipment construction and the development of cutting-edge technologies, which also have export potential on emerging markets. Unfortunately, despite several efforts to enhance economic policy in the environmental sector, nowadays the majority of technological innovations are focused on the extraction of fossil fuels, while green technologies, including RES, electric vehicles etc., are beyond the attention of the state, which once again emphasizes the focus of the country's economy. To adapt to the new energy landscape, it is necessary to change the model of growth, diversify the economy and elaborate a comprehensive development strategy, which will allow maintaining competitiveness and will determine the country's new position in the international arena.

\section{References}

1. OECD,

URL:

https://www.oecd.org/greengrowth/whatisgreengrowthandhowcanithelpdeliversustaina bledevelopment.htm

2. IEA Global Energy Review 2021, https://www.iea.org/reports/global-energy-review2021/ (2021)

3. Angora Energiewende and Ember (2021): The European Power Sector in 2020: Up-toDate Analysis on the Electricity Transition, URL: https://static.agoraenergiewende.de/fileadmin/Projekte/2021/2020_01_EU-Annual-Review_2020/AEW_202_Report_European-Power-Sector-2020.pdf (2021)

4. Federal State Statistics Service, URL: https://eng.rosstat.gov.ru (2021)

5. X. Dong, B. Wong, H. L. Yip, Q. N. Chan, CO2 Emission of Electric and Gasoline Vehicles under Various Road Conditions for China, Japan, Europe and World Average-Prediction through Year 2040, Appl. Sci. 9, 11 (2019)
6. Energy
Transition
Index
2021,
URL: http://www3.weforum.org/docs/WEF_Fostering_Effective_Energy_Transition_2021.p df 
7. Enerdata, URL: https://yearbook.enerdata.ru/renewables/renewable-in-electricityproduction-share.html (2021)

8. Energy strategy of the Russian Federation for the period up to 2035 / Approved by the order of the Government of the Russian Federation dated June 9, 2020 No. 1523-p

9. Russia Renewable Energy Development Association (RREDA), URL: https://rreda.ru/about-renewable-energy-industry

10. E. Tarkhanova, E. Lyapuntsova, N. Baburina, A. Fricler, The present and the future of Russian renewable energy in the green economy transition, E3S Web Conf. 250, 9 (2021)

11. Russia Renewable Energy Development Association (RREDA): report, URL: https://doc-0k-3c-

docs.googleusercontent.com/docs/securesc/af1 tsiihdpfmi7481tlvka74ap138sf2/jgenn4a c29msb19opl1vv94jthbr8p0o/1626960825000/18158831711336620583/06357517597 700155155/1iTma2Ksi_yZoL2zm9vJWHMKrfECm6c6i?e=download\&authuser=0\&n once $=$ idutohobilari\&user $=06357517597700155155 \&$ hash $=$ ui8uqi3jo74q2h9i97ct0h6t3 p91i7ne

12. R. Miskiewicz, Polityka Energetyczna, 21(2), 49-62 (2018)

13. R. Miskiewicz, Energies, 13(22), 6106 (2020)

14. R. Miśkiewicz, Journal of Risk and Financial Management, 14(2), 59 (2021)

15. K. Pająk, O. Kvilinskyi, O. Fasiecka, R. Miskiewicz, Economics and Environment, 2(61), 122-138, (2017)

16. P.W. Saługa, K. Szczepańska-Woszczyna, R. Miśkiewicz, M. Chłąd, Energies, 13(18), 4833 (2020)

17. Y. Kharazishvili, A. Kwilinski, O. Sukhodolia, H. Dzwigol, D. Bobro, J. Kotowicz, Energies, 14(8), 2126 (2021)

18. O. Lyulyov, I. Vakulenko, T. Pimonenko, A. Kwilinski, H. Dzwigol, M. DzwigolBarosz, Energies, 14(12), 3497 (2021)

19. V.V. Dementyev, A. Kwilinski, Journal of Institutional Studies, 12(1), 100-116 (2020)

20. A. Kuzior, A. Kwilinski, I. Hroznyi, Energies, 14(9), 2572 (2021)

21. Accelerating Wind Turbine Blade Circularity: report, URL: https:/windeurope.org/wpcontent/uploads/files/about-wind/reports/WindEurope-Accelerating-wind-turbineblade-circularity.pdf

22. IRENA, IEA-PV. End-of-life management. Solar photovoltaic panels, URL: https://www.irena.org//media/Files/IRENA/Agency/Publication/2016/IRENA_IEAPVPS_End-ofLife_Solar_PV_Panels_2016.pdf

23. E. Gavrikova, Y. Burda, V. Gavrikov, R. Sharafutdinov, I. Volkova, M. Rubleva, D. Polosukhina, Clean Energy Sources: Insights From Russia, Resources, 8(2), 84 (2019)

24. M. Pagliaro, Renewable energy in Russia: A critical perspective, SCI, 9, 8 (2021)

25. Moscow Mayor Official Website. New electric bus route in western Moscow, mos.ru, 15 August 2019, www.mos.ru/en/news/item/60142073 (2021)

26. Federal Law "On territories of advanced socio-economic development in the Russian Federation" dated 29.12.2014 N 473-Ф3

27. Bellona. Low-carbon development for the Russian - European region, URL: https://bellona.ru/2021/05/21/nizkouglerodnoe-razvitie-dlya-samogo-evropejskogoregiona/ 